\title{
RELAÇÃO ENTRE ESPAÇO E LUGAR E O VÍNCULO AFETIVO ENTRE ARQUITETURA E SOCIEDADE
}

\author{
Mariana Maia da Cruz Fernandes
}

Universidade do Oeste Paulista - UNOESTE. Curso de Arquitetura e Urbanismo. E-mail: marianamaia cf@hotmail.com

\section{RESUMO}

Quando discute-se em arquitetura a relação entre o que é o espaço e o que é o lugar, estes apresentam-se e entendem-se de maneira distintas. Sendo o espaço aquilo que sempre pretendemos alcançar, e o lugar o que é o conhecido. A relação espaço e lugar está atrelada a um vínculo de afetividade que a arquitetura, quando bem planejada, oferece à sociedade que a usa. Tais pontos apresentados são de extrema importância no ato de criar lugares e fornecer-lhes um uso adequado.

Palavras-chave: espaço, lugar, vínculo afetivo e sociedade

\section{RELATIONSHIP BETWEEN SPACE AND PLACE AND THE AFFECTIVE LINK BETWEEN ARCHITECTURE AND SOCIETY}

\begin{abstract}
When discussing in architecture the relationship between what is space and what is the place, they present themselves and understood to be of separate way. The space being always what we want reaching for and the place is known. The place and space relationship is linked to a connection of affection that the architecture, when well planned, provides the society that uses it. Such points presented are of utmost importance in the act of creating places and provide them with proper use.
\end{abstract}

Keywords: space, place, affective bond and society 


\section{INTRODUÇÃO E JUSTIFICATIVA}

Este artigo baseia-se em estudos realizados pela autora para a elaboração de seu trabalho de conclusão no curso de Arquitetura e Urbanismo. Uma parte dos estudos realizados, referem-se à relação de espaço e lugar, e também o vínculo de afetividade que uma arquitetura pode vir a ter com a sociedade à qual o seu uso se destina.

Tais estudos fazem-se importantes por refletirem aquilo que toda arquitetura deveria apresentar após seu término, no momento da real utilização; objetivo nem sempre alcançado, que pode gerar um futuro abandono e processo de degradação e até mesmo depredação por vândalos.

\section{ESPAÇO E LUGAR}

Quando fala-se em espaço e em lugar, várias definições apresentam-se; inicialmente têm aquelas definidas pelos dicionários, e posteriormente tem também aquelas que aqui serão explanadas, de acordo com alguns teóricos da área.

Para o geógrafo Milton Santos o espaço não qualifica-se da maneira tradicional como consta nos dicionários (geograficamente), ele adquire uma noção de tempo, permitindo o reconhecimento do movimento e apresentando as coisas de maneira heterogênea (SANTOS, 1982).

Otília Arantes, filósofa, também disserta acerca espaço e lugar. Em seu livro O Lugar da Arquitetura depois dos Modernos há inicialmente uma crítica à arquitetura modernista, onde Arantes afirma que a arquitetura era um lugar imposto à sociedade, dessa maneira não permitiase criar vínculo de afetividade entre o local e aqueles que o utilizavam. (ARANTES, 2000).

Arantes classifica o lugar de maneira diferente daquela proposta no modernismo, para ela lugar não se confunde com espaço físico; o espaço físico é aquele desprovido de significados, enquanto o lugar qualifica-se em um fato, acarretando significados. Cita Rossi ao dizer que a individualidade de um dado monumento está atrelada a um vínculo local, determinado pelo espaço, tempo e até memória. Cita ainda Gregotti, quando diz que uma arquitetura pode ter utilidade sem significados, e vice - versa:

[...] ou seja, é óbvia a existência de arquiteturas utilizáveis sem ser significantes, como também é óbvia a possibilidade de que um determinado monumento mantenha sua própria capacidade de ser significativo (ser precisamente, monumento de uma época), ainda que tenha perdido a possibilidade de seu uso prático ou que este se mantenha desconhecido para nós, e isso sem perder a capacidade de emitir mensagens acerca de sua própria estrutura. (ARANTES, 2000 apud GREGOTTI, 1978, p. 180-181) 
Prosseguindo com as definições, apresenta-se o não-lugar, apresentado por Marc Augé, que é exatamente o oposto do lugar. Se assim como diz Arantes, um lugar é dotado de significados históricos ou pessoais, o espaço que assim não o é, é classificado como um não-lugar. "Se um lugar pode se definir como identitário, relacional e histórico, um espaço que não pode se definir nem como identitário, nem como relacional, nem como histórico definirá um não-lugar." (AUGÉ, 2001, p. 73).

Sobre a criação de não-lugares, Augé acredita que a supermodernidade é a produtora deles. "O lugar e o não-lugar são, antes, polaridades fugidias: o primeiro nunca é completamente apagado e o segundo nunca se realiza totalmente [...]" (AUGÉ, 2001, p. 74). Ao citar Michel de Certeau, relata que para ele o espaço é o lugar praticado, ou seja, as pessoas são as responsáveis por fazerem do espaço da rua, um lugar.

Augé fala ainda da fenomenologia da percepção de Merleau-Ponty, onde há a diferença entre espaço geométrico e espaço antropológico como o espaço existencial, onde ensaia uma relação do homem conhecedor do meio em relação ao mundo.

Finalizando a pesquisa acerca autores que relatam sobre o tema abordado apresenta-se YiFu Tuan. Tuan (1983) diz que o lugar é tido como uma segurança e o espaço relaciona-se com a liberdade, onde a sociedade sempre está ligada àquele e buscando este. "O que começa como espaço indiferenciado transforma-se em lugar à medida que o conhecemos melhor e o dotamos de valor." (TUAN, 1983, p. 6).

Assim como Milton Santos, Tuan também classifica o espaço como uma unidade de movimento, e acrescenta que o lugar é a pausa "[...] cada pausa no movimento torna possível que localização se transforme em lugar." (TUAN, 1983, p. 6).

Para o autor, as pessoas obtém uma percepção do espaço através dos órgãos sensoriais, movimentos básicos de braços e pernas realizam tal conhecimento; e a mudança de um lugar a outro traz a noção de direção.

Tratando-se do lugar, Tuan apresenta a diferença de crianças e adultos ao percebê-lo. 0 adulto relaciona os lugares com diversos significados ao longo dos tempos, já a criança não o consegue definir assim, já que seu passado é curto e têm em vista um presente e passado imediatos. "Sua vitalidade para fazer coisas e explorar o espaço não condiz com a pausa reflexiva e com a olhada para trás que fazem com que os lugares pareçam saturados de significância." (TUAN, 1983, p. 37); e também "Quando o espaço nos é inteiramente familiar, torna-se lugar." (TUAN, 1983, p. 83). 
Em um âmbito mais pessoal, há a função social do ambiente construído, dissertada por Tuan (1983), onde o homem se conhece e atua melhor no ambiente realizado pelo próprio homem, do que em um ambiente natural; diz ele, que "[...] a arquitetura 'ensina'." (TUAN, 1983, p. 114). Finalizando sua teoria, Tuan diferencia lugar: "O lugar pode ser definido de diversas maneiras. Dentre elas, esta: lugar é qualquer objeto estável que capta nossa atenção." (TUAN, 1983, p. 179).

\section{VÍNCULO AFETIVO}

O vínculo afetivo que aqui será descrito, na verdade, nada mais é do que tudo o que já foi apresentado. No dado momento em que um espaço torna-se um lugar para os seres humanos, estes adquirem um determinado vínculo com o lugar. Tomando-o como próprio e cuidando da mesma forma.

Para contextualizar com as teorias de espaço e lugar, são estudados teóricos que explanam sobre o ambiente escolar. Apresentam a relação de afetividade que as crianças podem ter com o ambiente construído.

Doris Kowaltowski tem dizeres importantes sobre a educação infantil. A autora classifica a educação como uma transferência de valores e conhecimentos a cada geração, classificando-a assim como a própria história da sociedade. Kowaltowski (2011) afirma que a sociedade exerce uma função de educadora sobre as crianças, mas cabe à família o papel principal.

Um dos pontos muito discutido por Kowaltowski é o método educacional de Jean Piaget, do início do século XX. Piaget estudou a evolução do pensamento de uma criança até a sua adolescência para entender a forma com que captavam o mundo. Esta teoria é fundamentada no interacionismo, a criança é um ser dinâmico que interage com objetos e pessoas. "A interação social favorece a aprendizagem e esta necessita estruturar-se de modo a privilegiar a colaboração, a cooperação e o intercâmbio de pontos de vista na busca conjunta do conhecimento." (KOWALTOWSKI, 2011, p. 21).

Kowaltowski (2011) também relata sobre a percepção do espaço, podendo esta ocorrer pessoalmente ou socialmente, levando em consideração dados como cultura e a sensação de medo ou segurança que uma arquitetura pode oferecer. A autora explana sobre conceitos que relacionam a interatividade do homem com o espaço: privacidade, o indivíduo atua no ambiente de acordo com seu ponto de vista; espaço pessoal, a pessoa cria limites para impedir aproximações indesejáveis; espaço territorial, o homem cria demarcações que mostram que o meio pertence à ele ou vise versa; e densidade territorial, influencia no bem-estar do indivíduo de 
acordo com questões de proximidade e coletividade. "[...] estuda-se como a arquitetura influencia e satisfaz, ou não a vivência de cada usuário, fornecendo subsídios a futuros projetos ou introduzindo melhorias nas edificações existentes." (KOWALTOWSKI, 2011, p. 42).

Outros autores também abordam o assunto da teoria interacionista e o vínculo de afetividade. Azevedo, Rheingantz e Bastos (2004) dizem que para uma arquitetura suprir o desejo dos usuários, é fundamental que cada indivíduo apreenda o espaço de uma maneira e estabeleça uma relação com o mesmo.

Adultos quando questionados sobre a escola da infância reproduzem a imagem de um lugar impregnado de significados, experiências afetivas e valores, trazendo sensações de alegria, segurança, bem-estar e conforto, ou até mesmo o inverso destas. Todas essas vivências sociais e cognitivas revelam uma dinâmica de relações além do espaço tridimensional, trazendo uma significação de 'lugar' para os usuários. (AZEVEDO, RHEINGANTZ, BASTOS, 2004, p.2).

Azevedo relata que quando um grupo de pessoas se apropriam de um espaço, estes apresentam relacionamento diferente dos demais. "[...] lugares que favoreçam sua apropriação e transformação por sua própria ação no sentido de conhecerem o ambiente sem medos, encorajando-os a participar de sua organização." (AZEVEDO, 2012, p. 3497).

Azevedo (2012) ainda diz que para a interatividade acontecer, é eficaz minimizar a distância entre espaço interno e externo, não sendo o externo limitado pelo terreno, e sim estendendo pela cidade através das ruas e praças. Com esses dizeres de Azevedo, volta-se para o que diz Kowaltowski (2011).

Kowaltowski disserta acerca o vandalismo nas escolas e as formas de preveni-lo; que não se limita aos ambientes escolares, e sim estende-se a toda a arquitetura como um todo. Ao se realizar pesquisas para compreender como prevenir a degradação nas escolas, algumas soluções construtivas surtiram pontos positivos, “[...] para uma relação afetiva com o prédio escolar, transformando-o em um espaço significativo para a comunidade atendida." (KOWALTOWSKI, 2011, p. 44).

Finalizando, ambientes humanizados, uma escala pequena, elementos de decoração, paisagismo e características residenciais são pontos apresentados por Kowaltowski (2011) para uma maior aceitação do ambiente por parte dos usuários, levando a um comportamento social adequado. "As causas do vandalismo são complexas, mas um ambiente físico agradável e constantemente bem-mantido, com um detalhamento que iniba a ação dos vândalos, pode contribuir para diminuir esses atos." (KOWALTOWSKI, 2011, p. 44-45). 


\section{CONCLUSÃO}

Diante de tais teorias apresentadas e explicadas: relação espaço e lugar, gerando um vínculo de afetividade e um interacionismo por parte da sociedade; é possível perceber a importância das mesmas para o cotidiano. É de grande importância para a inteireza de uma arquitetura, assim como a integridade de uma sociedade.

Em outras palavras, ao se atingir tais requisitos em uma arquitetura, ao estabelecer essa afetividade com a população, o trabalho será mútuo; tanto a arquitetura é favorecida no presente e historicamente, quanto a sociedade é favorecida adquirindo melhores valores para o futuro.

\section{REFERÊNCIAS}

ARANTES, O. B. F. O lugar da arquitetura depois dos modernos. 3 ed. São Paulo: Editora da Universidade de São Paulo, 2000.

AUGÉ, M. Não-lugares: introdução a uma antropologia da supermodernidade. 2 ed. Campinas: Papirus, 2001.

AZEVEDO, G. A. N. Sobre o papel da arquitetura escolar no cotidiano da educação: análise das interações pessoa-ambiente para a transformação qualitativa do lugar pedagógico. XIV ENTAC Encontro Nacional de Tecnologia do Ambiente Construído, Juiz de Fora, p. 3494-3504, out. 2012. Disponível em: <http://www.gae.fau.ufrj.br/arq_pdf/artigos/Giselle\%20Arteiro\%20Nielsen\%20Azevedo/sobre\%2 0o\%20papel\%20da\%20arquitetura\%20escolar\%20no\%20cotidiano\%202012.pdf> Acesso em: 24 mai. 2014.

AZEVEDO, G.; RHEINGANTZ, P. A.; BASTOS, L. E. G. O espaço da escola como o "lugar" do conhecimento: um estudo de avaliação de desempenho com abordagem interacionista. 2004. 10f. Artigo (Programa de pós-graduação em arquitetura - PROARQ) - Universidade Federal do Rio de Janeiro, Rio de Janeiro. Disponível em: <http://www.gae.fau.ufrj.br/arq_pdf/artigos/esp_esc_\%20lugar_conh.pdf> Acesso em: 24 mai. 2014.

KOWALTOWSKI, D. C. C. K. Arquitetura escolar: o projeto do ambiente de ensino. São Paulo: Oficina de Textos, 2011.

SANTOS, M. O espaço geográfico como categoria filosófica. In: 5o ENCONTRO NACIONAL DE GEÓGRAFOS, 1982, Porto Alegre. Disponível em: <http://posgeografiaunir.files.wordpress.com/2011/07/milton-santos-o-espac3a7ogeogrc3a1fico-como-categoria-filosc3b3fica.pdf> Acesso em: 27 mai. 2014.

TUAN, YI-FU. Espaço e lugar: a perspectiva da experiência. São Paulo: DIFEL, 1983. 